This item was submitted to Loughborough's Research Repository by the author.

Items in Figshare are protected by copyright, with all rights reserved, unless otherwise indicated.

\title{
Modelling the high temperature behaviour of TBCs using sequentially coupled microstructural-mechanical FE analyses
}

PLEASE CITE THE PUBLISHED VERSION

http://dx.doi.org/10.1016/j.msea.2009.02.006

PUBLISHER

(c) Elsevier

VERSION

AM (Accepted Manuscript)

LICENCE

CC BY-NC-ND 4.0

\section{REPOSITORY RECORD}

Hermosilla, U., M. Karunaratne, I.A. Jones, Tom H. Hyde, and Rachel C. Thomson. 2014. "Modelling the High Temperature Behaviour of Tbcs Using Sequentially Coupled Microstructural-mechanical FE Analyses". figshare. https://hdl.handle.net/2134/15322. 
This item was submitted to Loughborough's Institutional Repository (https://dspace.lboro.ac.uk/) by the author and is made available under the following Creative Commons Licence conditions.

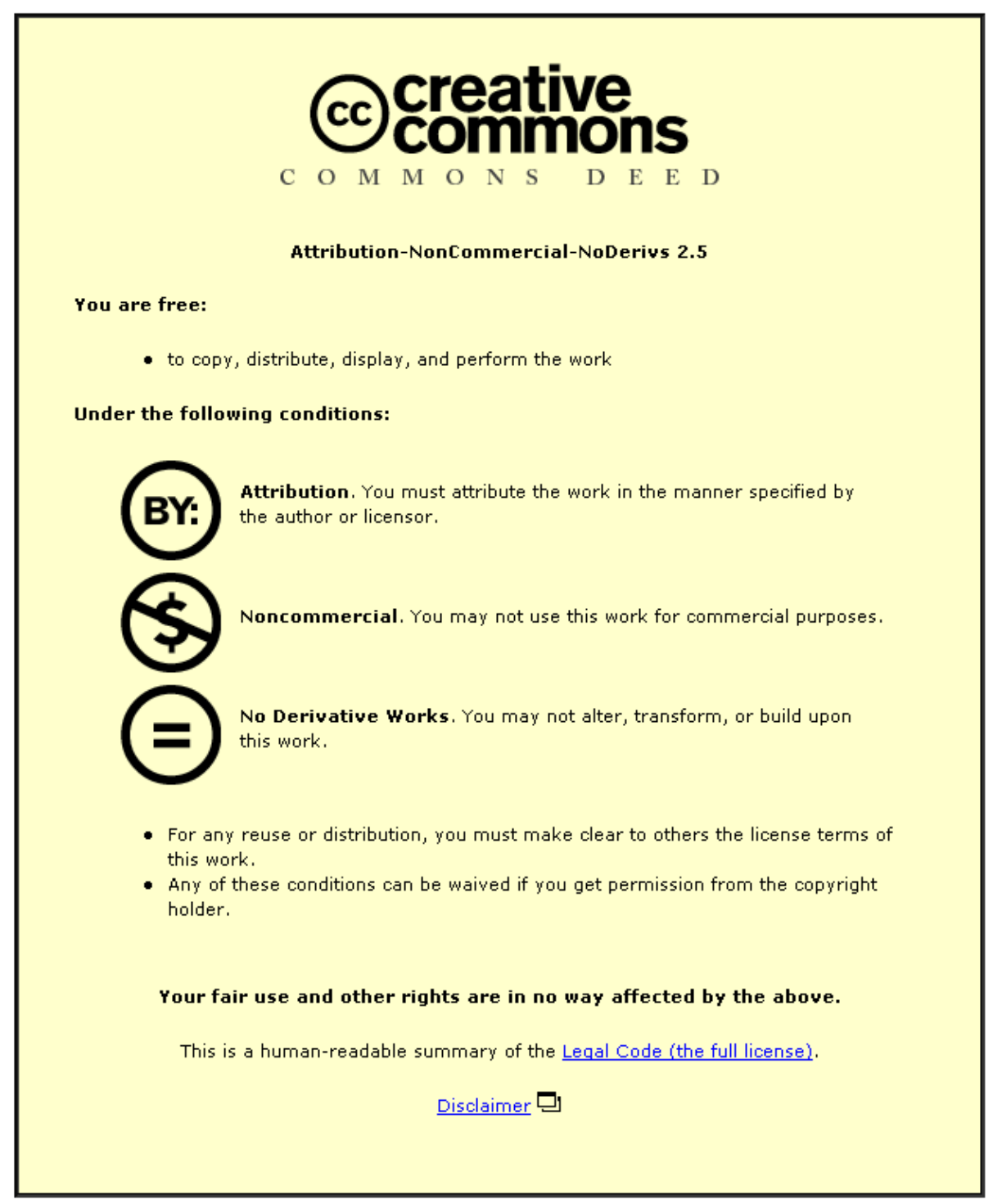

For the full text of this licence, please go to: http://creativecommons.org/licenses/by-nc-nd/2.5/ 


\title{
Modelling the high temperature behaviour of TBCs using sequentially coupled microstructural-mechanical FE analyses
}

\author{
U. Hermosilla $^{\text {a }}$, M. S. A. Karunaratne ${ }^{\text {b }}$, I. A. Jones ${ }^{\text {a,* }}$, \\ T. H. Hyde ${ }^{\mathrm{a}}$, R. C. Thomson ${ }^{\mathrm{b}}$ \\ ${ }^{a}$ School of Mechanical, Materials and Manufacturing Engineering, University of \\ Nottingham, Nottingham, NG7 2RD, UK \\ ${ }^{\mathrm{b}}$ IPTME, University of Loughborough, Loughborough, LE11 3TU, UK
}

\begin{abstract}
Thermal barrier coatings provide a means of thermal insulation of gas turbine components exposed to elevated temperatures. They undergo severe microstructural changes and material degradation, which have been implemented in this work by means of a sequentially coupled microstructural mechanical calculation that made use of a self-consistent constitutive model within finite element calculations. Analyses for different temperatures and bond coat compositions were run, which reproduced the trends reported in previous research and identified the accumulation of high out-of-plane tensile stresses within the alumina layer as an additional phenomenon that could drive high temperature crack nucleation.
\end{abstract}

Key words: Thermal barrier coating, finite element analysis, Eshelby, creep, oxidation, stress accumulation

* Corresponding author. Tel.: +44 115 9513784; fax +11 1159513800.

Email address: arthur.jones@nottingham.ac.uk (I. A. Jones). 


\section{Introduction}

Thermal barrier coatings (TBCs) provide a means of thermal insulation that can be applied to Ni-based superalloys and hence increase the high temperature resistance of components made from them. TBCs are composed of a

5 ceramic top coat (TC) of $\sim 100-200 \mu \mathrm{m}$ thickness of partially stabilized zirconia, i.e. $\mathrm{ZrO}_{2}-7$ wt $\% \mathrm{Y}_{2} \mathrm{O}_{3}$ (PSZ) applied using either the atmospheric plasma spraying (APS) technique $[1,2]$ or the electron-beam physical vapour deposition (EB-PVD) $[2,3]$ technique; the TC acts as the thermal insulator. A thermally grown oxide (TGO) of $\sim 1-10 \mu \mathrm{m}$ composed mainly of alumina develops underneath the TC. A bond coat (BC) of $\sim 100 \mu$ m guarantees both a smooth transition in the coefficient of thermal expansion (CTE) and good chemical bonding with the substrate material. BCs can be composed of (Ni,Pt)Al or MCrAlY, where M stands for $\mathrm{Ni}$, Co or a combination of both. This layer is usually deposited on the surface of the Ni-based superalloy and provides a source of $\mathrm{Al}$ for the TGO, which acts as an oxidation barrier for the underlying material. However, as the TGO grows when exposed to high temperatures, stresses are induced in both the TC and BC.

TBCs are mainly used for the thermal insulation of internally cooled gas turbine blades and combustion chamber components. The presence of the TBC creates a temperature drop so that, for a given level of air cooling within the blade, a higher combustion gas temperature can be tolerated. Alternatively a 
lower substrate temperature is produced, increasing the blade's lifetime.

Three different sources contribute to the development of stress in TBCs: (i) CTE mismatch, (ii) oxidation and growth of the TGO and its associated volume change, and (iii) externally applied load. Items (i) and (ii) are investigated in the present paper, but (iii) adds a further dimension to the set of parameters defining the problem and has therefore not been investigated here. Creep of the layers acts as a stress relieving mechanism, the stress at different points of the TBC being a result of the interaction of those phenomena. Hence, it is crucial to represent in a reliable manner the creep behaviour of the different layers.

Therefore, it is desirable to be able to use a fundamental approach to estimate the creep behaviour of MCrAlY bond coats of arbitrary composition. Since MCrAlYs can be regarded as multiphase alloys, a complete understanding of their high temperature behaviour should not only take into account the temperature dependency of the initial isolated phases, but the microstructural changes which occur with time and temperature variations as well.

The microstructural data that define the phase changes and oxidation of the bond coat were obtained by means of a combined thermodynamic and kinetic model $[4,5]$ that couples a calculation of phase equilibrium with a finite difference model of diffusion of elements in metallic alloys. These calculations simulate the diffusion of elements between the substrate material and the bond 
coat in TBCs. The results of the calculations consist of the microstructural evolution at different temperatures, specifically the phase proportions at each 45 spatial position as a function of time. The TGO growth is simulated within the model and coupled with the diffusion of the oxide-forming elements, notably aluminium.

The TGO growth is caused by two parallel phenomena: the inward oxygen diffusion from the external hot gas stream and the outward diffusion of oxidationprone elements, mainly aluminium. The interdiffusion of elements through the different layers creates particular zones where some elements or phases may not be present at certain times and different phases may have formed instead, hence changing the mechanical properties and behaviour of the material; the main example of this phenomenon being the softening of the bond coat, in terms of creep, which occurred upon $\beta$ depletion.

Coupled microstructural-mechanical models have been previously used by Busso et al. [6-8] in order to model the formation of oxide. However, the TGO layer was assumed to be composed of a mixture of alumina and an oxidation resistant phase, i.e. $\gamma-\mathrm{Ni}$, even in the fully oxidised state. The oxidation process was simulated by means of the evolution of a function that progressed gradually from an initial value of 0 to a final value of 1 , which represented the fully oxidised state, driven by the concentration of oxygen calculated from a diffusion analysis run prior to the structural analysis. The implementation of this model resulted in a gradual oxidation of the bond coat, which implied that 
65 of oxide at the same time throughout the analysis, in contrast with the clear interface between the two layers (bond coat alloy and oxide) that experimental observation shows.

Due to the ranges of stress and temperatures to which TBCs are exposed, the main material properties to take into account are the elastic, coefficient of thermal expansion and creep properties of the composing layers and individual phases. Research carried out using Eshelby's [9] inclusion technique to obtain homogenization relations applicable for both the calculation of elastic constants [10] and for the modelling of inelastic behaviours [11] such as creep the thermal expansion of a multiphase aggregate based on some of the results obtained by Wakashima et al. [12] will also be presented.

The model described in this paper is used to study the accumulation of stresses at high temperature caused primarily by oxidation. TBCs typically fail upon cooling from high temperature, but a certain amount of high temperature exposure is required for spallation to occur, implying that the oxidation and degradation of coated specimens creates the critical conditions that are responsible for failure upon cooling, i.e. failure of TBCs is not driven by thermal shock alone, and high temperature processes play a critical role in the origin 85 of the debonding of the layers. 


\section{Constitutive model}

The constitutive model used in this paper to simulate the behaviour of the bond coat and TGO, which incorporates the effect of the microstructural degradation and oxidation at high temperature, accounts for non-isothermal and inelastic behaviour.

The aggregate stress, in rate form and assuming small material rotation, is expressed as

$$
\dot{\boldsymbol{\sigma}}=\mathbf{C}:\left(\dot{\boldsymbol{\epsilon}}-\dot{\boldsymbol{\epsilon}}^{i n}\right)-3 K \alpha \dot{T} \mathbf{1}
$$

where $\dot{\boldsymbol{\sigma}}$ is the aggregate stress rate tensor, $\mathbf{C}$ the elastic tensor, $\dot{\boldsymbol{\epsilon}}$ the aggregate total strain rate tensor, $\dot{\boldsymbol{\epsilon}}^{i n}$ the aggregate inelastic strain rate tensor, $K$ the aggregate bulk modulus, $\alpha$ the aggregate coefficient of thermal expansion and $\dot{T}$ the rate of temperature change. The aggregate inelastic strain rate tensor, $\dot{\boldsymbol{\epsilon}}^{i n}$, is composed of two parts, the strain rate tensor corresponding to creep, $\dot{\boldsymbol{\epsilon}}^{c r}$, and the transformation strain rate tensor, $\dot{\boldsymbol{\epsilon}}^{\text {tr }}$, originated from the volume expansion that the precipitation of new oxide causes. The aggregate inelastic strain tensor is then formulated as

$$
\dot{\boldsymbol{\epsilon}}^{i n}=\dot{\boldsymbol{\epsilon}}^{c r}+\dot{\boldsymbol{\epsilon}}^{t r}
$$


with the aggregate creep strain tensor obtained as:

$$
\dot{\boldsymbol{\epsilon}}^{c r}=\sum_{g} f^{g} \dot{\boldsymbol{\epsilon}}^{g, c r}
$$

where $f^{g}$ is the volume proportion at which phase $g$ is present and $\dot{\boldsymbol{\epsilon}}^{g, c r}$ is its corresponding creep strain rate tensor. The transformation strain rate is:

$$
\dot{\boldsymbol{\epsilon}}^{t r}=\frac{1}{3} \dot{f}^{o x} \ln \left(P B R_{e q}\right) \mathbf{1}
$$

which imposes an isotropic volume expansion to the newly deposited oxide. $\dot{f}^{o x}$ is the rate at which oxide is being formed and $P B R_{e q}$ the bond coat equivalent Pilling-Bedworth ratio, calculated following Equation 9.

Finally, the equation that links the stress-strain states in the aggregate, $\dot{\boldsymbol{\sigma}}$, and in the phases that compose it, $\dot{\boldsymbol{\sigma}}^{m}$, is, expressed in rate form [11]:

$$
\dot{\boldsymbol{\sigma}}^{m}=\dot{\boldsymbol{\sigma}}+2 \mu\left(1-\beta_{t}\right)\left(\dot{\boldsymbol{\epsilon}}^{c r}-\dot{\boldsymbol{\epsilon}}^{m, c r}\right)
$$

where $\beta_{t}=\frac{2(4-5 \nu)}{15(1-\nu)}$, obtained as the result of the application of Eshelby's fourth order tensor, $\mathbf{S}$, to the case of a dispersion of spherical inclusions. Equations 1 - 5 are solved using an explicit-implicit numerical algorithm within the FE code ABAQUS by means of the UMAT user material subroutine [13]. 


\subsection{Additional considerations}

The elastic tensor, $\mathbf{C}$, used in Equation 1 is fully defined by two elastic constants for isotropic materials. In this work, the elastic constants of the aggregate have been calculated using the expressions originally derived by Budiansky [10] using Eshelby's inclusion technique, as

$$
\begin{aligned}
& \sum_{i=1}^{N} \frac{f^{i}}{1+\beta_{t}\left(\frac{G^{i}}{G}-1\right)}=1 \\
& \sum_{i=1}^{N} \frac{f^{i}}{1+\beta_{n}\left(\frac{K^{i}}{K}-1\right)}=1
\end{aligned}
$$

where $\beta_{t}=\frac{2(4-5 \nu)}{15(1-\nu)}$ as previously, $\beta_{n}=\frac{1+\nu}{3(1-\nu)}, \nu=\frac{3 K-2 G}{6 K+2 G}$ and the $i$ superscript

refers to each of the composing phase.

The coefficient of thermal expansion, $\alpha$, is calculated using an expression derived upon the same hypotheses used by Wakashima et al. [12], modified to make use of the self-consistency approach and generalised to take into account the presence of several phases, yielding

$$
\alpha=\frac{\sum_{g} f^{g} \frac{K^{g}}{K^{g}+\frac{2-4 \nu}{1+\nu} K} \alpha^{g}}{\sum_{g} f^{g} \frac{K^{g}}{K^{g}+\frac{2-4 \nu}{1+\nu} K}}
$$

where $\alpha^{g}$ are the CTEs of the phases present in the aggregate.

The Pilling-Bedworth ratio assumed in this work was calculated as an equiv- 
alent value for a multiphase alloy according to

$$
P B R_{e q}=\sum_{g} f^{g} P B R^{g}
$$

where $P B R^{g}$ is the Pilling-Bedworth ratio of the phase $g$, defined as the ratio of the volume of formed oxide to the volume of consumed metal during oxidation. The methodology here merits a brief explanation. As there is no evidence that the TGO layer is formed from discrete regions made up of oxides of elements in the same proportions as the phases in the underlying bond coat, the simple rule-of-mixtures approach is used, and no attempt is made to treat the TGO layer as a particulate composite via a self-consistent model.

\section{Material properties}

Calculations have been run assuming a typical configuration of a coated component, i.e. an IN-738LC base material with an MCrAlY bond coat and a plasma-sprayed PSZ top coat. Two alternative compositions were taken into account for the bond coat, namely LCO22 and PWA276, in order to assess any possible influence of their composition in the developed stress levels. The implementation of the different bond coat compositions is carried out by the use of their specific phase proportions as a function of temperature and time.

The properties of the IN-738LC alloy have been extracted from Ref. [14]. 
Its nominal composition is given in Table 1. Temperature dependent elastic constants (see Table 2) and coefficient of thermal expansion, shown in Table 3, were used [14]. Secondary creep data provided in Ref. [14] were fitted using the least squares method to a Norton-type equation [15] as shown in Equation 10

$$
\dot{\boldsymbol{\epsilon}}^{m, c r}=\frac{3}{2} A_{0}^{m} e^{-\frac{Q^{m}}{R T}}\left(\sigma^{m}\right)^{n^{m}-1} \mathbf{s}^{m}
$$

where the creep exponent, $n^{m}$, was linearly interpolated between the two temperatures for which it is given in Table 4 in order to use the numerical values that provide the best approximation to the available experimental data.

APS PSZ is known to undergo a sintering process when it is exposed to high temperature. However, based on experimental data obtained by Thompson and Clyne [16], a Young's modulus of 20 GPa was assumed for the temperature range considered in this study. A value of 0.18 for its Poisson's ratio was assumed as done by Busso et al. [7]. Zhu and Miller [17] obtained the creep properties of a plasma sprayed zirconia 8 wt\% yttria ceramic coating using experimental data produced under laser imposed temperature and stress gradients. The primary creep stage was found to be representative in the overall behaviour of the coating, which reflects in the time hardening behaviour presented in Equation 11 through the exponent, s, given in Table 4,

$$
\dot{\epsilon}=A_{0} e^{-\frac{Q}{R T}} \sigma^{n} t^{-s}
$$


The temperature-dependent coefficient of thermal expansion of the PSZ is given in Table 3. The method of obtaining the creep constants that define the behaviour of the phases present in bond coats is explained in a companion paper [18] and the elastic constants and CTEs are listed in Tables 2 and 3 respectively.

$\mathrm{Xu}$ and Wei [19] provide data of the Pilling-Bedworth ratios of $\gamma^{\prime}$ and $\beta ; 1.795$ and 1.71 were used in this analysis, respectively. No oxidation expansion was assumed for $\gamma$ and $\sigma$, which effectively implies that the volume expansion upon oxidation is proportional to the fraction of aluminium-containing phases, i.e. ${ }_{135} \beta$ and $\gamma^{\prime}$.

The TGO grows according to the equation

$$
h=\left(k_{p}^{\prime} t\right)^{n_{o x}} \Rightarrow \dot{h}=n_{o x}\left(k_{p}^{\prime} t\right)^{n_{o x}-1} k_{p}^{\prime}=n_{o x}\left(k_{p}^{\prime}\right)^{n_{o x}} t^{n_{o x}-1}
$$

where $k_{p}^{\prime}$ is the growth constant, $n_{o x}$ the growth exponent and $t$ the time. The growth constant is calculated as:

$$
k_{p}^{\prime}=e^{Q\left(\frac{1}{T_{0}}-\frac{1}{T}\right)}[\mu \mathrm{m}, \mathrm{K}, \mathrm{s}]
$$

which makes use of the activation energy, $Q$, and reference temperature, $T_{0}$, given in Table 5. 


\section{Finite element model}

\subsection{Geometry and meshing}

140

2 by plotting the aspect ratio, $\frac{a}{L}$ against the wavelength, $L$, for the TBCs 
considered here. Wavelength values seem to be dependent upon the manufacturing process, but the dependency of the aspect ratio on the manufacturing process seems to be weaker.

A probability distribution chart can be generated from the data in Fig. 2. This distribution, shown in Fig. 3, is obtained by projecting the data points in Fig. 2 onto the ordinates axis and grouping these values into discrete intervals. Realistic geometric parameters, that define the typical interface waviness found in TBCs, can be extracted from Fig. 2. The distribution is shown to be somewhat skewed, with around $80 \%$ of the points corresponding to aspect ratios of less than around 0.27 , and the remainder forming a long tail and possibly a further cluster somewhere around $\frac{a}{L}=0.33$.

In this work, a series of parametric studies has been run. Several combinations of geometric parameters have been used, as shown in Table 8, considering three alternative interface geometries extracted from the data depicted in Figs. 2 and 3, with $48 \mu \mathrm{m}$ wavelength and $6 \mu \mathrm{m}$ amplitude, $24 \mu \mathrm{m}$ and $8 \mu \mathrm{m}$, and $48 \mu \mathrm{m}$ wavelength and $12 \mu \mathrm{m}$ amplitude respectively. These values of $a$ and $L$ were chosen to give ratios of $1: 8,1: 3$ and $1: 4$ respectively; the first two of these combinations correspond (in round figures) to the ratios in the main cluster, in the possible second cluster, and the third gives an intermediate ratio. Calculations with initial TGO thicknesses of 1,3 and $5 \mu \mathrm{m}$ have been carried out on the $48 \mu \mathrm{m}$ wavelength and $6 \mu \mathrm{m}$ amplitude model, in order to study the dependency of the stresses with that parameter. An initial oxide 
thickness of $1 \mu \mathrm{m}$ was assumed for the rest of the models. The values of aspect ratio $\frac{a}{L}$ used for the models are marked on the Figs. 2 and 3 .

Axisymmetric 4-node reduced integration elements have been used in the analysis, as they produce reliable results in creep-related problems [13]. Fig. 4 shows a detail view of the mesh in the TGO proximity. Different mesh densities have been used, with the highest mesh density being near the position of most interest, i.e. the TGO, and the coarser mesh being in the areas far from that position of most interest.

Fig. 5 shows the boundary conditions applied to the model. The axial displacements are restrained for the left surface, enforcing symmetry about that plane. All the nodes on the right surface have the same axial displacement, again enforcing a symmetric strain field. These constraints ensure that the model can represent an infinitely-repeating region under uniaxial loading. The radial displacements of the nodes on the axis of rotational symmetry are set to zero in order to enforce simulation of a solid cylinder.

\subsection{Integration of FE and microstructural data}

Fig. 6 shows diagrammatically the information flow and coupling of the microstructural and mechanical analyses. The microstructural calculations introduced in $\S 1$ [5] were performed in a $1 \mathrm{D}$ finite difference model, producing tables of phase proportions at each depth into the coating and substrate as 
a function of time, temperature and substrate composition. At the time of performing the work, the microstructural calculations had not been extended from the basic $1 \mathrm{D}$ case to consider $2 \mathrm{D}$ or $3 \mathrm{D}$ geometries, due to a combination of the complexity of the model (and associated numerical stability issues) and the computationally-intensive nature of the phase stability calculations which underly it. It was therefore necessary to map the results from the $1 \mathrm{D}$ models onto the 2D axisymmetric meshes used for the structural finite element modelling, necessitating an interpolation process as the discretisation of the $1 \mathrm{D}$ and 2D meshes does not match. The interpolation process is illustrated in Fig. 7, which shows how the depth $x$ from the TGO/bond coat boundary is used to interpolate linearly from the results of the 1D model. The interpolated values of the volume proportion of each phase in the bond coat are written to ABAQUS *.fil files (using a Fortran [27] program compiled using the abaqus make facility [13]) as "field variables"; in the case of the TGO layer, there is a single phase corresponding to alumina. The files of field variables are then read by the ABAQUS solver and used within a UMAT user-defined material model subroutine which implements the constitutive model described in $\S 2$, to define the behaviour of the bond coat and the oxide layer within the mechanical analysis. 


\section{$5 \quad$ Results and discussion}

sents either bond coat or alumina, not a continuously-varying mixture of the two, and the "jumps" occur as an element (or layer of elements) changes from 
bond coat to alumina (and expands according to its Pilling-Bedworth ratio) in

240

245 higher $\frac{a}{L}$ ratios.

Similar observations regarding TC valley stresses can be made, as shown in Figs. 10 and 11. In this case the stresses are compressive and the oxidation process imposes a compressive stress rate except for the low $\frac{a}{L}$ with LCO22 bond

order to represent an increment of movement of the bond coat/TGO boundary. Convergence was studied as far as practical computation times permitted, demonstrating that the overall accumulated stresses and strains due to oxidation did not significantly depend upon the mesh or maximum strain increment used. In this case, the same phenomenon occurs as was found for TBCs with LCO22 bond coats, i.e. higher tensile stress levels and stress rates occur for

coat. When a certain value of $\frac{a}{L}$ is exceeded, the oxidation process is reflected in the accumulation of compressive stress in the top coat valley point. This process is more intense when PWA276 bond coats are assumed, as these have a higher aluminium content and thus higher $\gamma^{\prime}$ and $\beta$ proportions resulting in a greater equivalent PBR according to Equation 9.

255 The trends in the growth stresses at the top coat peak point are consistent with other published calculations [7], which show that the oxidation produces tensile stresses at that location with increasing thermal exposure [20]. This phenomenon is more prevalent the higher the $\frac{a}{L}$ ratio is. The trends in the oxidation stresses obtained using the model presented in this paper contrast with those obtained if the growth of the oxide layer is modelled by means 
of a swelling strain rate imposed to the oxide layer as in Refs. [23, 29-31], for which the TC peak experiences compression and the valley tensile stresses [23]. The models presented here make some simplifying assumptions regarding the use of a macroscopically isotropic self-consistent model and isotropic bond coat structure and behaviour. These were adopted for reasons of practicality, particularly with regard to the limited availability of data for input into homogenisation models. The influence of these assumptions has not been explored, but remains an area requiring further investigation in the future.

\subsection{Effect of temperature}

The temperature dependency of the top coat peak stresses is shown in Fig. 12. Lower temperatures imply slower oxidation rates, which do not produce tensile stresses in the TC peak locations. Fig. 12 clearly shows that the PWA276 bond coat produces higher tensile stresses in the top coat peak location than the LCO22 alloy. These stresses are originated by its higher content in oxidationprone phases such as $\gamma^{\prime}$ and $\beta$ due to its higher content in aluminium.

\subsection{TGO growth stress}

More noteworthy than the evolution of the top coat stresses is the development of stress within the oxide layer. Since oxide formation is accompanied by a volume expansion according to the Pilling-Bedworth ratio of the alloy, 
the precipitated oxide is initially subjected to compressive stresses caused by the presence of the surrounding material layers. In order to study the stress evolution of the oxide layer, a study is made of the radial stresses in the element in the central location between the peak and valley points adjacent to the initial oxide layer, i.e. the "TGO centre" location in Fig. 4, is considered.

Fig. 13 shows the stress evolution at the location previously identified when an LCO22 bond coat is assumed. The effect of different initial oxide thicknesses, $h_{0}$, can be assumed to be minor compared with the imperfection aspect ratio, $\frac{a}{L}$. The first part of the graph shows a steep addition of compressive stress that arises from the restriction to the expansion imposed by the surrounding material. From that point, and as the oxide grows and its interface with the bond coat advances inwards into that layer, the oxide created at the beginning of the analysis begins to accumulate tensile stress, which originates as a reaction to the expansion attempts of the additional oxide being formed. This accumulation of tensile stress at high temperature may be the origin of the cracks within the oxide layer reported in Refs. [6,32] after high temperature exposure.

A similar situation, although with higher stress levels, appears when a PWA276 bond coat is assumed as in Fig. 14. In this case, the intensity of the stresses and the rate at which they change is noticeably higher due to the higher content of aluminium and oxidation-prone phases in this alloy, causing the stresses to reach values over $1 \mathrm{GPa}$. 
A comparison of the effect of temperature in both type of TBCs is given in Fig. 15, which shows its very significant effect in the development of tensile stress. The steep changes in the stress values is due to the severe volume changes that arise upon the creation of new oxide.

\section{Conclusions}

A coupled microstructural-mechanical model has been implemented using the finite element method. The microstructural results from a one dimensional finite difference diffusion model, which simulated the material degradation and phase transformation upon thermal exposure, were imported into ABAQUS [13] by means of post-processing programs compiled using the abaqus make execution procedure. A material user subroutine, based on a self-consistent scheme (which extends the concept of Eshelby's inclusion technique [9] to consider non-dilute inclusion volume fractions) models the bond coat as a multiphase aggregate taking into account the properties of each individual phase that composes it.

The TGO growth is modelled by changing the microstructure of the bond coat elements adjacent to the oxide layer to that of pure alumina and imposing a volumetric expansion according to the PBR of the oxidation reaction. The PBR used in this paper was calculated as the equivalent value taking into account the individual ratios of the phases that compose the bond coat alloy 
and its microstructure. However, in view of the impact of this parameter in the achieved stress levels, further investigations into the estimation of that ratio are needed.

Additionally, the simplifications assumed in the composition and mechanical properties of the phases imply that aluminium is not present in the $\gamma$ phase, neglecting the contribution to alumina formation of that phase. Another source of stress in the bond coat/TGO vicinity is that reported by Tolpygo and Clarke [33], who suggested that the $\beta \rightarrow \gamma^{\prime}$ reaction was accompanied by a volume contraction that would influence the stress levels achieved.

Analyses were run for two different temperatures, $800^{\circ} \mathrm{C}$ and $900^{\circ} \mathrm{C}$, for a 1000 $\mathrm{h}$ exposure time. All the material layers were assumed to creep at elevated temperature. Stresses at peak and valley points of the top coat and at the centre of the bond coat adjacent to the initial oxide layer, which represents the first fraction of oxide being formed, were studied, leading to the following conclusions:

- The effect of TGO oxidation and growth on the top coat is the accumulation of tensile stresses in the peak location. However, the results for low $\frac{a}{L}$ ratios do not show any stress accumulation, suggesting the existence of a critical imperfection aspect ratio, $\frac{a_{c}}{L}$, under which stresses in the top coat do not accumulate.

- Of the two bond coats studied in this work, the PWA276 alloy, which is 
richer in aluminium, produces higher stress levels than LCO22. The severity of the oxidation model creates abrupt jumps in the stress with time, a phenomenon that is believed to be due to the discrete nature of FE modelling.

- Growth of the TGO produces an inverse effect on the TC valley locations when compared to peak points; the stress normal to the interface, or equivalently the radial stress in the models used in this work, accumulated compressive stress upon oxidation, this process being more intense for higher temperatures, $\frac{a}{L}$ ratios and for higher $\mathrm{Al}$ contents in the bond coat.

- Stress values in the vicinity of the initial oxide layer, i.e. the first oxide formed, reveal that they experience a fast compression arising because the Pilling-Bedworth ratio of the bond coat alloy is higher than unity. That process is typically followed by the accumulation of tensile stresses perpendicular to the TGO/TC interface imposed by the oxide that forms subsequently, reaching in some cases levels over $1 \mathrm{GPa}$.

- Tensile stresses accumulate in the oxide layer; these stresses may be responsible for in-plane cracking of the TGO layer and cause partial debonding and crack initiation at high temperature. This creates the critical conditions for subsequent top coat spalling upon cooling to room temperature. 


\section{Acknowledgements}

The authors gratefully acknowledge the support of the Engineering and Physical Sciences Research Council (EPSRC) via the SuperGen 2 Plant Lifetime

Extension project (grant no. GR/586334/01).

\section{References}

[1] H. Herman and C. C. Berndt, in: Thermal barrier coating workshop, NASA Conf. Pub. 3312, 1995, pp. 127-134.

[2] L. B. Chen. Surf. Rev. Lett. 13 (2006) 535-544.

[3] D. V. Rigney, R. Viguie and D. J. Wortman, in: Thermal barrier coating workshop, NASA Conf. Pub. 3312, 1995, pp. 135-149.

[4] R. H. Davies, A. T. Dinsdale, J. A. Gisby, J. A. J. Robinson, S. M. Martin, CALPHAD 26 (2002) 229-271.

[5] M. S. A. Karunaratne, S. L. Ogden, S. D. Kenny and R. C. Thomson, A 375 multicomponent diffusion model for the prediction of microstructural evolution in coated Ni-based superalloy systems. Accepted for publication in Mater. Sci. Tech.

[6] E. P. Busso, J. Phys. IV 9 (1999) 287-296.

[7] E. P. Busso, J. Lin, S. Sakurai, M. Nakayama, Acta Mater. 49 (2001) 1515-1528.

[8] E. P. Busso, J. Lin, S. Sakurai, Acta Mater. 49 (2001) 1529-1536. 
[9] J. D. Eshelby, Proc. Roy. Soc. Lond. A 241 (1957) 376-396.

[10] B. Budiansky, J. Mech. Phys. Solids 13 (1965) 223-227.

[11] B. Budiansky, T. T. Wu, Proc. fourth U.S. Nat. Cong. Appl. Mech. 2 (1962) $1175-1185$.

[12] W. Wakashima, M. Otsuka, S. Umekawa, J. Compos. Mater. 8 (1974) 391-404.

[13] Hibbitt, Karlsson \& Sorenssen, Inc., ABAQUS Analysis User's Manual, version $6.5-1,2004$.

[14] Alloy IN-738 Technical Data, The International Nickel Company Inc. 15C1-81 5789,1981

[15] R. K. Penny, L. Marriott. Design for creep, second ed., Chapman \& Hall, London, 1995.

[16] J. A. Thompson, T. W. Clyne, Acta Mater. 49 (2001) 1565-1575.

[17] D. Zhu, R. A. Miller, Determination of creep behavior of thermal barrier coatings under laser imposed temperature and stress gradients, Tech. Memo. 113169, NASA, 1997.

[18] U. Hermosilla, M. S. A. Karunaratne, I. A. Jones, T. H. Hyde, R. C. Thomson, MCrAlY creep behaviour modelling by means of finite element unit cells and self-consistent constitutive equations. Accepted for publication in Proc. I. Mech. Eng. L - J. Mater.

400

[19] C. Xu, W. Gao, Mater. Res. Innov. 3 (2000) 231-235. 
[20] A. M. Freborg, B. L. Ferguson, W. J. Brindley, G. J. Petrus, Mater. Sci. Eng. A 245 (1998) 182-190.

[21] M. Y. He, A. G. Evans, J. W. Hutchinson, Acta Mater. 48 (2000) 2593-2601.

[22] J. Rösler, M. Bäker, M. Volgmann, Acta Mater. 49 (2001) 3659-3670.

[23] J. Rösler, M. Bäker, K. Aufzug, Acta Mater. 52 (2004) 4809-4817.

[24] M. Y. He, J. W. Hutchinson, A. G. Evans, Acta Mater. 50 (2002) 1063-1073.

[25] M. Y. Ali, S. Q. Nusier, G. M. Newaz, Int. J. Solids Struct. 38 (2001) 3329-3340.

[26] M. Karunaratne, Personal Communication.

[27] D. M. Etter, Structured FORTRAN 77 for Engineers and Scientists, fourth ed., Benjamin/Cummings, Redwood City, Calif., 1993.

[28] T. Xu, M. Y. He, A. G. Evans, Acta Mater. 51 (2003) 3807-3820.

[29] A. M. Karlsson, A. G. Evans, Acta Mater. 49 (2001) 1793-1804.

[30] A. M. Karlsson, C. G. Levi, A. G. Evans, Acta Mater. 50 (2002) 1263-1273.

[31] A. M. Karlsson and T. Xu and A. G. Evans, Acta Mater. 50 (2002) 1211-1218.

${ }_{415}$ [32] E. P. Busso, L. Wright, H. E. Evans, L. N. McCartney, S. R. J. Saunders, S. Osgerby, J. Nunn, Acta Mater. 55 (2007) 1491-1503.

[33] V. K. Tolpygo, D. R. Clarke, Acta Mater. 48 (2000) 3283-3293.

[34] P. Majerus, $\quad$ Neue $\quad$ Verfahren Analyse des Verformungs- und Schädigungsverhaltens von MCrAlY-Schichten 
im Wärmedämmschichtsystem. PhD thesis, Fakultät für Maschinenwesen der Rheimisch-Westfälischen Technischen Hochschule Aachen, 2003.

[35] M. G. Hebsur, R. V. Miner, Mater. Sci. Eng. 83 (1986) 239-245.

[36] H. J. Frost, M. F. Ashby, Deformation-mechanism maps: the plasticity and creep of metals and ceramics, Pergamon, Oxford, 1982.

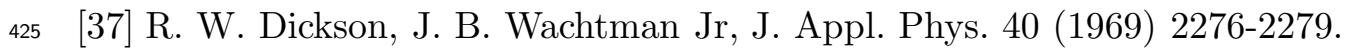

[38] R. B. Ross, Metallic materials specification handbook, fouth edition, Chapman \& Hall, London, 1992.

[39] N. S. Stoloff, V. K. Sikka, Physical metallurgy and processing of intermetallic compounds, Chapman \& Hall, New York, 1996.

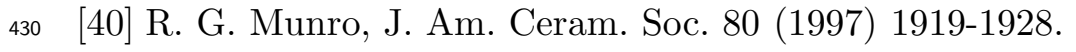

[41] J. T. DeMasi, K. D. Sheffler, M. Ortiz, Thermal Barrier Coating Life Prediction Model Development. Phase I - Final Report, NASA, Tech. Rep. CR-182230, 1989.

[42] L. A. Hocking, P. R. Strutt, R. A. Dodd, J. Inst. Metals, 99 (1971) 98-101.

435 [43] J. D. Whittenberger, J. Mater. Sci., 22 (1987) 394-402.

[44] W. J. Yang, R. A. Dodd, Metal Sci. J., 7 (1973)41-47.

[45] R. R. Vandervoort, A. K. Mukherjee, J. E. Dorn, Trans. ASM, 59 (1966) 931-944

[46] M. Rudy, G. Sauthoff, Mater. Res. Soc. Symp. Proc. 39 (1985) 327-333.

[47] J. Wolfenstine, H. K. Kim, J. C. Earthman, Mater. Sci. Eng. A, 192-193 (1994) 811-816. 
[48] S. M. Meier, D. M. Nissley, K. D. Sheffler, Thermal Barrier Coating Life Prediction Model Development. Phase II - Final Report, NASA, Tech. Rep. CR-189111 (1991). 


\section{Tables}

\begin{tabular}{cccc}
\hline Element wt\% & IN-738LC, [14] & LCO22 [34] & PWA 276 [35] \\
\hline $\mathrm{Ni}$ & 61 & 32 & 48.29 \\
$\mathrm{C}$ & 0.11 & - & 0.01 \\
$\mathrm{Co}$ & 8.5 & 38.5 & 20.3 \\
$\mathrm{Cr}$ & 16 & 21 & 17.3 \\
$\mathrm{Mo}$ & 1.75 & - & - \\
$\mathrm{W}$ & 2.6 & - & - \\
$\mathrm{Ta}$ & 1.75 & - & - \\
$\mathrm{Nb}$ & 0.9 & - & - \\
$\mathrm{Al}$ & 3.4 & 8 & 13.6 \\
$\mathrm{Ti}$ & 3.4 & - & - \\
$\mathrm{Al}+\mathrm{Ti}$ & 6.8 & - & - \\
$\mathrm{B}$ & 0.01 & - & - \\
$\mathrm{Zr}$ & 0.05 & - & - \\
$\mathrm{Fn}, \mathrm{Si}, \mathrm{S}$ & low as possible & - & 0.5 \\
$\mathrm{Y}$ & - & 0.5 & \\
\hline
\end{tabular}

Table 1

Nominal compositions of substrate and bond coats. 


\begin{tabular}{|c|c|c|c|c|c|c|}
\hline$\underbrace{\underset{0}{\circlearrowright}}_{E}$ & 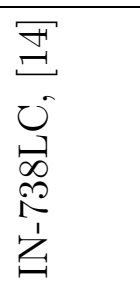 & 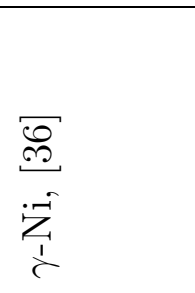 & 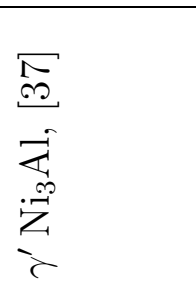 & 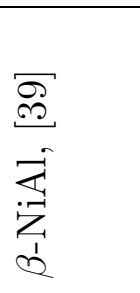 & $\begin{array}{l}\overline{0} \\
\tilde{\omega} \\
\dot{0} \\
\dot{0}\end{array}$ & 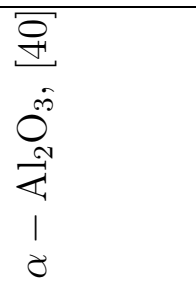 \\
\hline 10 & - & - & $\begin{array}{l}184.536 / \\
0.32\end{array}$ & - & - & - \\
\hline 20 & - & - & - & - & - & $416 / 0.231$ \\
\hline 23.9 & $\begin{array}{l}200.6 / \\
0.28\end{array}$ & - & - & - & - & - \\
\hline 27.0 & - & $\begin{array}{l}206.718 / \\
0.31\end{array}$ & - & $\begin{array}{l}188.0 / \\
0.313\end{array}$ & $\begin{array}{l}304.92 / \\
0.21\end{array}$ & - \\
\hline 93.3 & $\begin{array}{l}195.1 / \\
0.27\end{array}$ & - & - & - & - & - \\
\hline 204.4 & $\begin{array}{l}190.3 / \\
0.27\end{array}$ & - & - & - & - & - \\
\hline 315.6 & $\begin{array}{l}184.8 / \\
0.28\end{array}$ & - & - & - & - & - \\
\hline 426.7 & $\begin{array}{l}179.3 / \\
0.28\end{array}$ & - & - & - & - & - \\
\hline 537.8 & $\begin{array}{l}175.1 / \\
0.30\end{array}$ & - & - & - & - & - \\
\hline 648.9 & $\begin{array}{l}167.6 / \\
0.30\end{array}$ & - & - & - & - & - \\
\hline 760 & $\begin{array}{l}157 / \\
0.3\end{array}$ & - & - & - & - & - \\
\hline 850 & - & - & $\begin{array}{l}142.2568 / \\
0.337\end{array}$ & - & - & - \\
\hline 871.1 & $\begin{array}{l}151 / \\
0.29\end{array}$ & - & - & - & - & - \\
\hline 982.2 & $\begin{array}{l}140 / \\
0.30\end{array}$ & - & - & - & - & - \\
\hline 1000 & - & $\begin{array}{l}132.1366 / \\
0.31\end{array}$ & - & $\begin{array}{l}150.0 / \\
0.313\end{array}$ & $\begin{array}{l}236.3377 / \\
0.21\end{array}$ & - \\
\hline 1500 & - & - & - & - & - & $338 / 0.252$ \\
\hline
\end{tabular}

Table 2

Elastic properties of materials, $E(\mathrm{GPa}) / \nu$. 


\begin{tabular}{|c|c|c|c|c|c|c|c|}
\hline$\underbrace{\underset{0}{O}}_{E}$ & 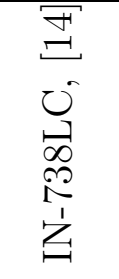 & $\begin{array}{l}\infty \\
\infty \\
\stackrel{\infty}{\infty} \\
\stackrel{i}{c} \\
\dot{c}\end{array}$ & 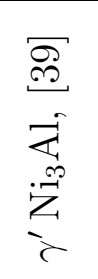 & 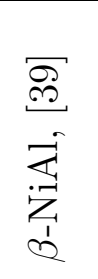 & $\begin{array}{l}\infty \\
\infty \\
\stackrel{\infty}{\infty} \\
\dot{J} \\
\dot{b}\end{array}$ & 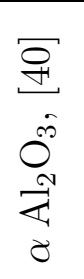 & 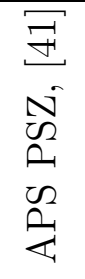 \\
\hline 20 & - & 13.1 & - & 13.2 & 6.2 & - & - \\
\hline 23.9 & 11.23 & - & - & - & - & - & - \\
\hline 27.0 & - & - & 12.5 & - & - & - & - \\
\hline 93.3 & 11.97 & - & - & - & - & - & - \\
\hline 100 & - & - & - & - & - & - & 8.82 \\
\hline 200 & - & - & - & - & - & - & 9.4 \\
\hline 204.4 & 13.23 & - & - & - & - & - & - \\
\hline 300 & - & - & - & - & - & - & 9.75 \\
\hline 315.6 & 14.4 & - & - & - & - & - & - \\
\hline 400 & - & - & - & - & - & - & 10 \\
\hline 426.7 & 15.46 & - & - & - & - & - & - \\
\hline 500 & - & - & - & - & - & 8.3 & 10.2 \\
\hline 537.8 & 16.2 & - & - & - & - & - & - \\
\hline 600 & - & - & - & - & - & - & 10.4 \\
\hline 648.9 & 16.63 & - & - & - & - & - & - \\
\hline 700 & - & - & - & - & - & - & 10.5 \\
\hline 27.0 & - & - & 16.8 & - & - & - & - \\
\hline 760 & 18.38 & - & - & - & - & - & - \\
\hline 800 & - & - & - & - & - & - & 10.6 \\
\hline 871.1 & 19.42 & - & - & - & - & - & - \\
\hline 900 & - & - & - & - & - & - & 10.7 \\
\hline 962.2 & 20.7 & - & - & - & - & - & - \\
\hline 1000 & - & - & - & - & - & - & 10.8 \\
\hline 1100 & - & - & - & - & - & - & 10.9 \\
\hline 1175 & - & - & - & - & - & - & 11.0 \\
\hline 1500 & - & - & - & - & - & 9.7 & - \\
\hline
\end{tabular}

Table 3

$\mathrm{CTE} \times 10^{6}$ of materials $\left({ }^{\circ} \mathrm{C}^{-1}\right)$. 


\begin{tabular}{|c|c|c|c|c|c|}
\hline Material & 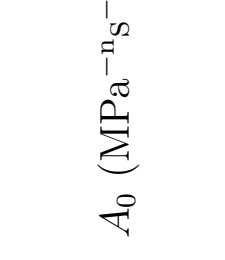 & $\begin{array}{c}\overrightarrow{1} \\
\overrightarrow{0} \\
\dot{a} \\
\dot{\vec{a}} \\
0\end{array}$ & 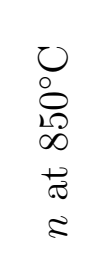 & 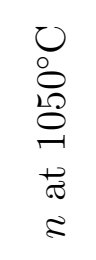 & $s$ \\
\hline IN-738LC, [14] & $6.68 \times 10^{48}$ & 1721 & 9.96 & 6.6 & - \\
\hline$\alpha-\mathrm{Al}_{2} \mathrm{O}_{3},[40]$ & 415.12 & 325 & 1.08 & 1.08 & - \\
\hline YSZ [17] & 0.026 & 104.5 & 0.56 & 0.56 & 0.67 \\
\hline $\operatorname{NiAl}(\beta)[39,42-46]$ & $2.18 \times 10^{-1}$ & 315.0 & 5.42 & 5.42 & - \\
\hline $\mathrm{Ni}(\gamma)[36]$ & $2.79 \times 10^{5}$ & 381.0 & 5.42 & 4.90 & - \\
\hline $\operatorname{Cr}(\sigma)[36]$ & $1.24 \times 10^{4}$ & 384.0 & 4.94 & 4.48 & - \\
\hline $\mathrm{Ni}_{3} \mathrm{Al}\left(\gamma^{\prime}\right)[47]$ & $8.19 \times 10^{-14}$ & 26.8 & 3.14 & 4.30 & - \\
\hline
\end{tabular}

Table 4

Creep properties of materials.

Table 5

\begin{tabular}{ll}
\hline Parameter & Value \\
\hline$Q$ & $27777.4 \mathrm{~K}$ \\
$T_{0}$ & $2423.7 \mathrm{~K}$ \\
$n_{o x}$ & 0.332 \\
\hline
\end{tabular}

Parameters used in TGO growth calculation. $Q, T_{0}$ and $n_{o x}$ were extracted from Ref [48].

Table 6

\begin{tabular}{cc}
\hline Layer & Thickness \\
\hline Substrate & $2 \mathrm{~mm}$ \\
Bond coat & $225 \mu \mathrm{m}$ \\
TGO & $h_{0}$ (parameter) \\
Top coat & $178 \mu \mathrm{m}$ \\
\hline
\end{tabular}

Model dimensions. 
Table 7

\begin{tabular}{cccc}
\hline TBC number & $\bar{L}, \mu \mathrm{m}$ & $\bar{a}, \mu \mathrm{m}$ & $\frac{\bar{a}}{\bar{L}}$ \\
\hline 1 & 64.8 & 9.7 & 0.157 \\
2 & 27.7 & 3.3 & 0.154 \\
3 & 37.5 & 7.1 & 0.226 \\
4 & 51.8 & 8.2 & 0.171 \\
\hline
\end{tabular}

Wavelength, amplitude and aspect ratio averages for the imperfections in the TBCs from Ref. [26]

Table 8

\begin{tabular}{cc}
\hline Parameter & Value \\
\hline$A$ & $6-8-12 \mu \mathrm{m}$ \\
$h$ & $1-3-5 \mu \mathrm{m}$ \\
$L$ & $24-48 \mu \mathrm{m}$ \\
\hline
\end{tabular}

TBC geometric parameters. 
Fig. 12. Effect of temperature and bond coat composition on the TC peak radial stress evolution with time.

Fig. 13. TGO centre radial stress evolution with time at $900^{\circ} \mathrm{C}$ using dif485

Fig. 14. TGO centre radial stress evolution with time at $900^{\circ} \mathrm{C}$ using different geometric parameters, assuming a PWA 276 bond coat. 
490 Fig. 15. Effect of temperature and bond coat composition on the TGO centre radial stress evolution with time. 

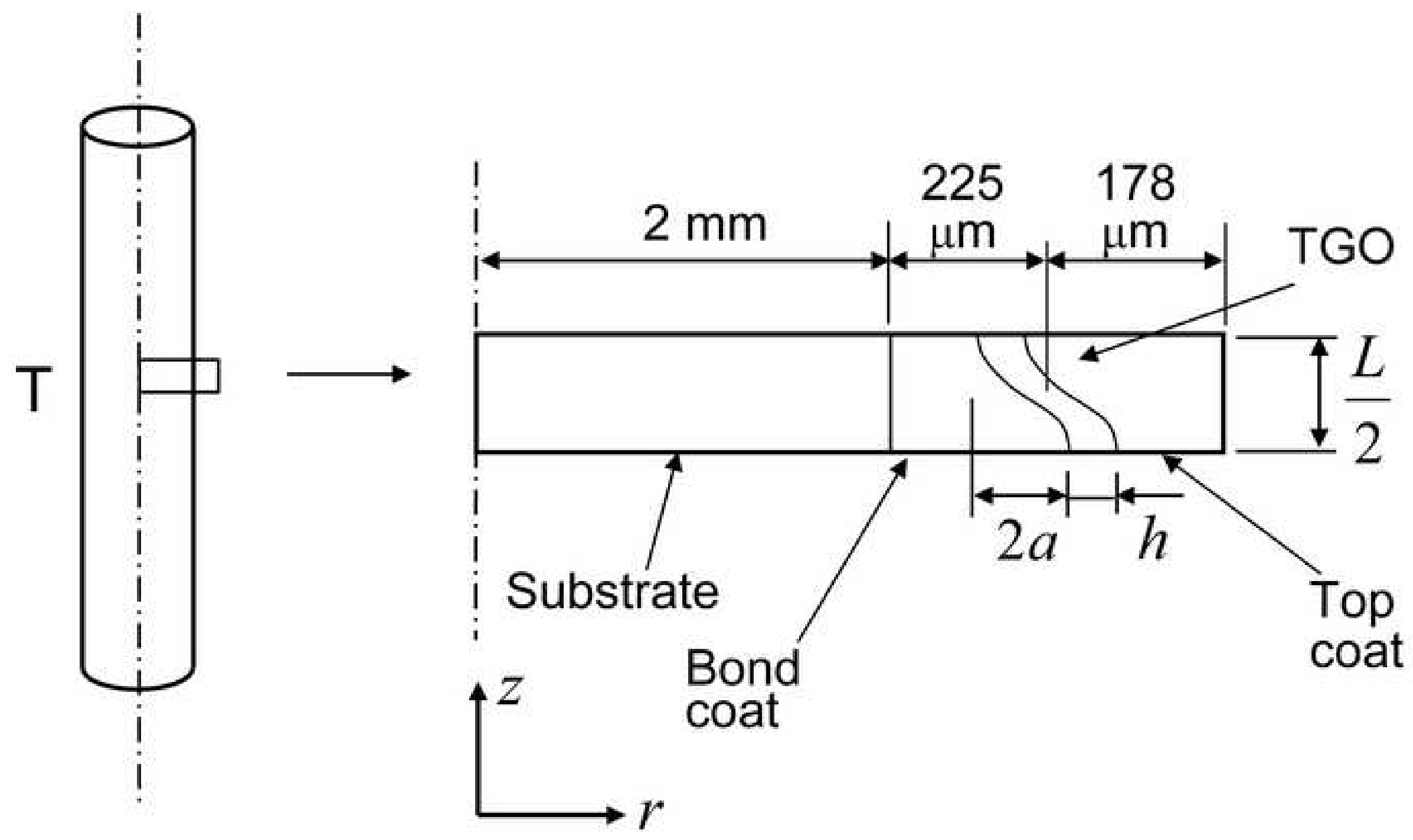


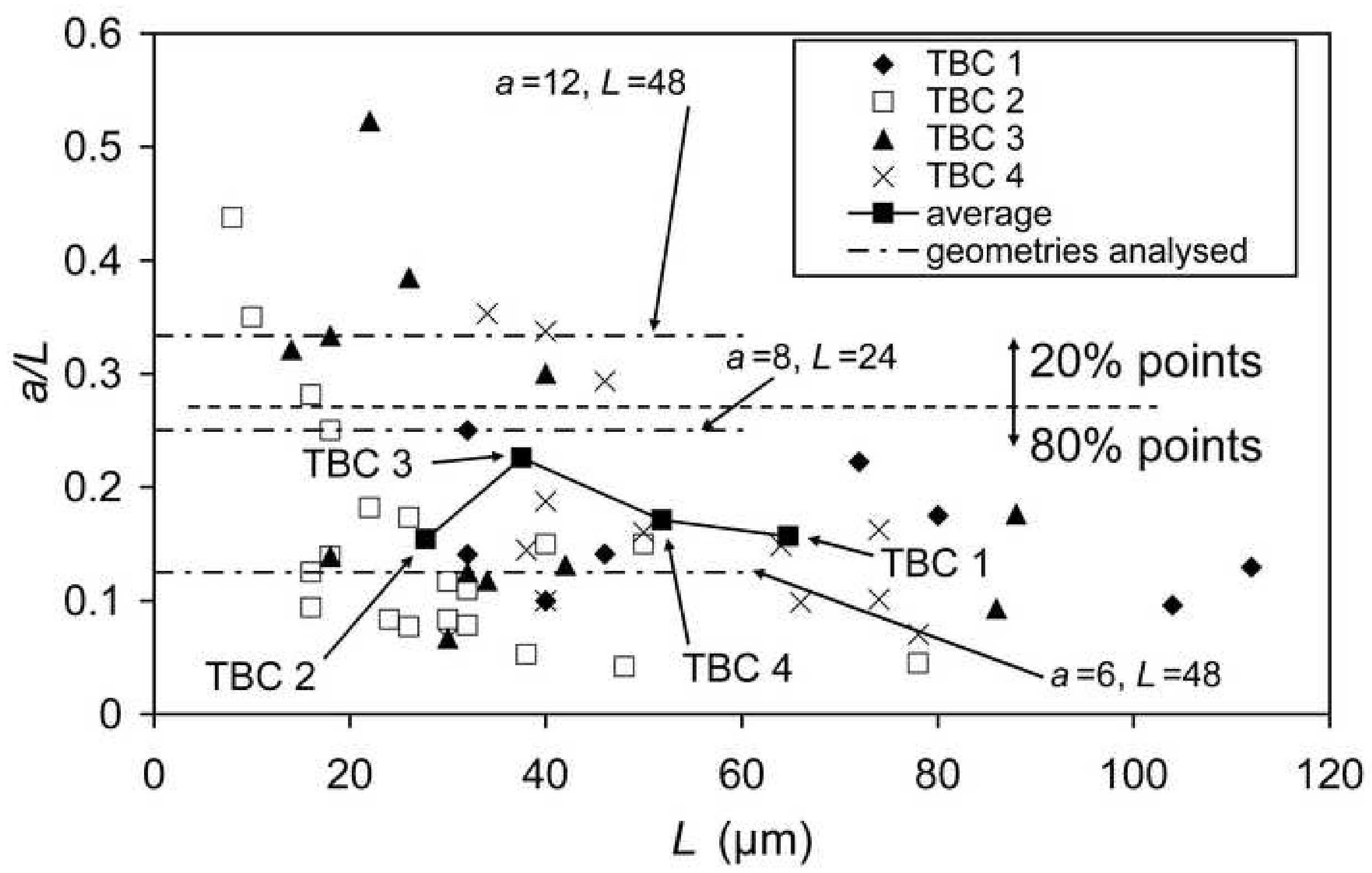




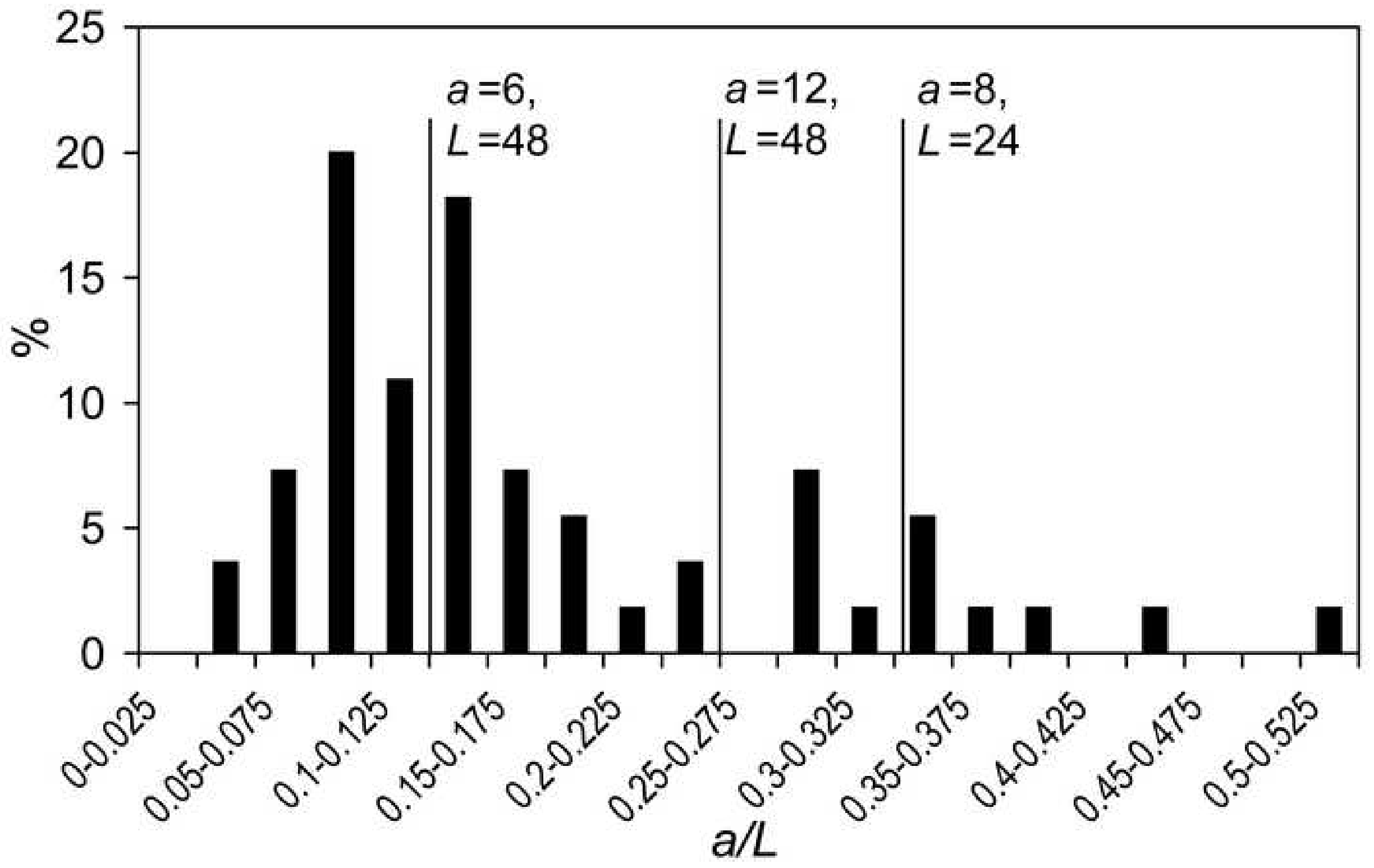




\section{conditions}

Click here to download high resolution image

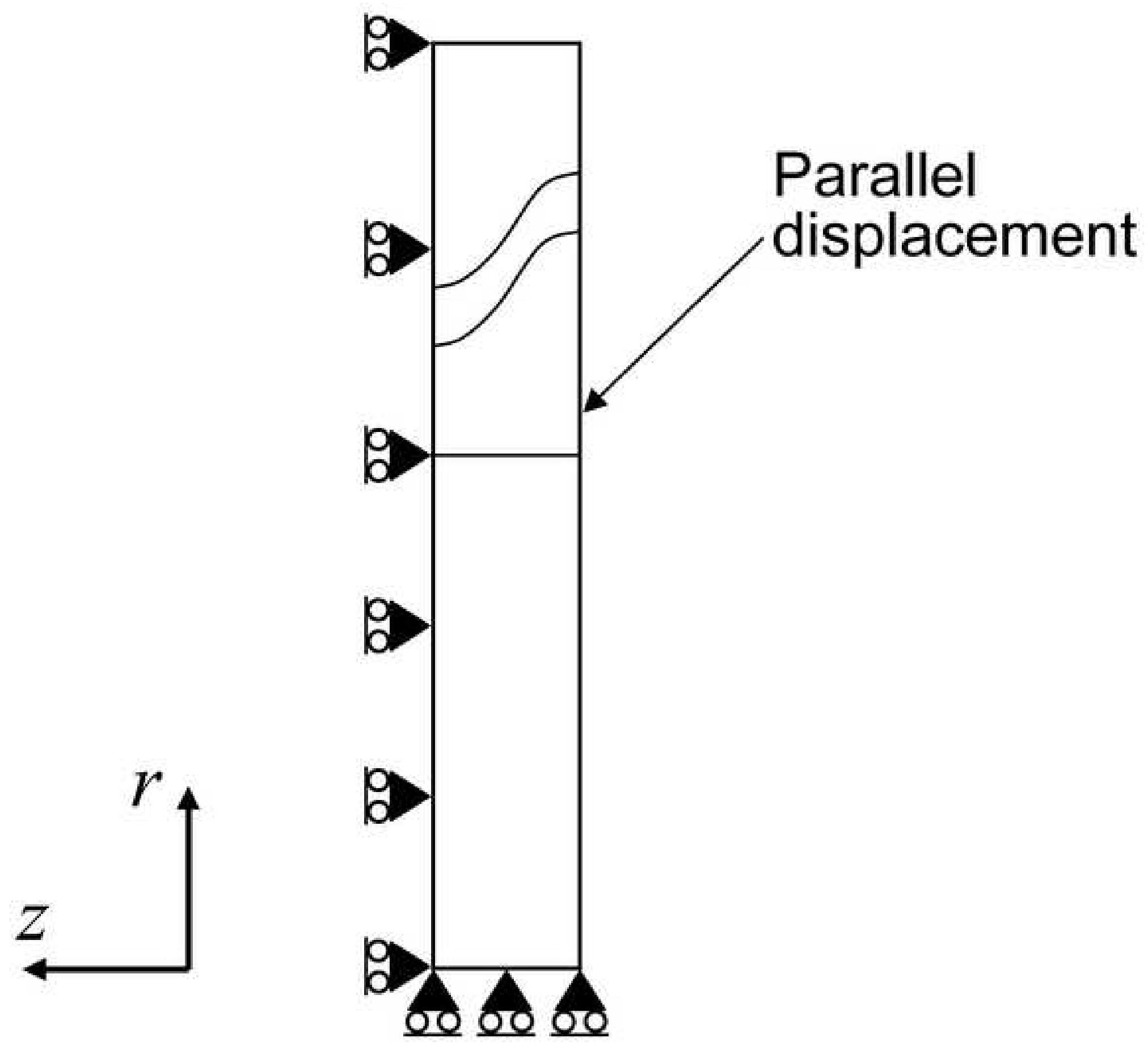




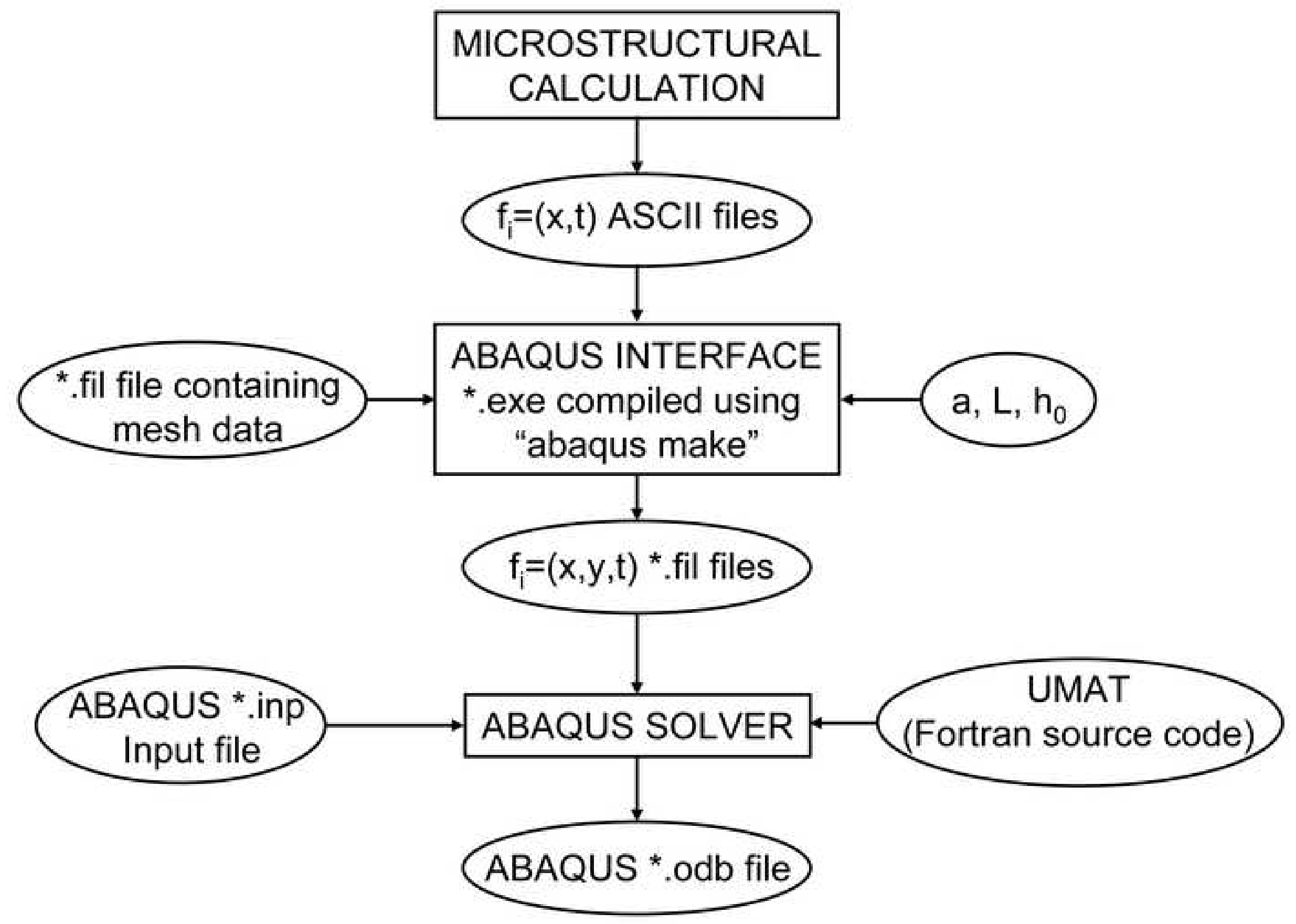

ABAQUS INTERFACE .exe compiled using "abaqus make"

$$
f_{i}=(x, y, t){ }^{*} \text {.fil files }
$$

ABAQUS *.odb file 


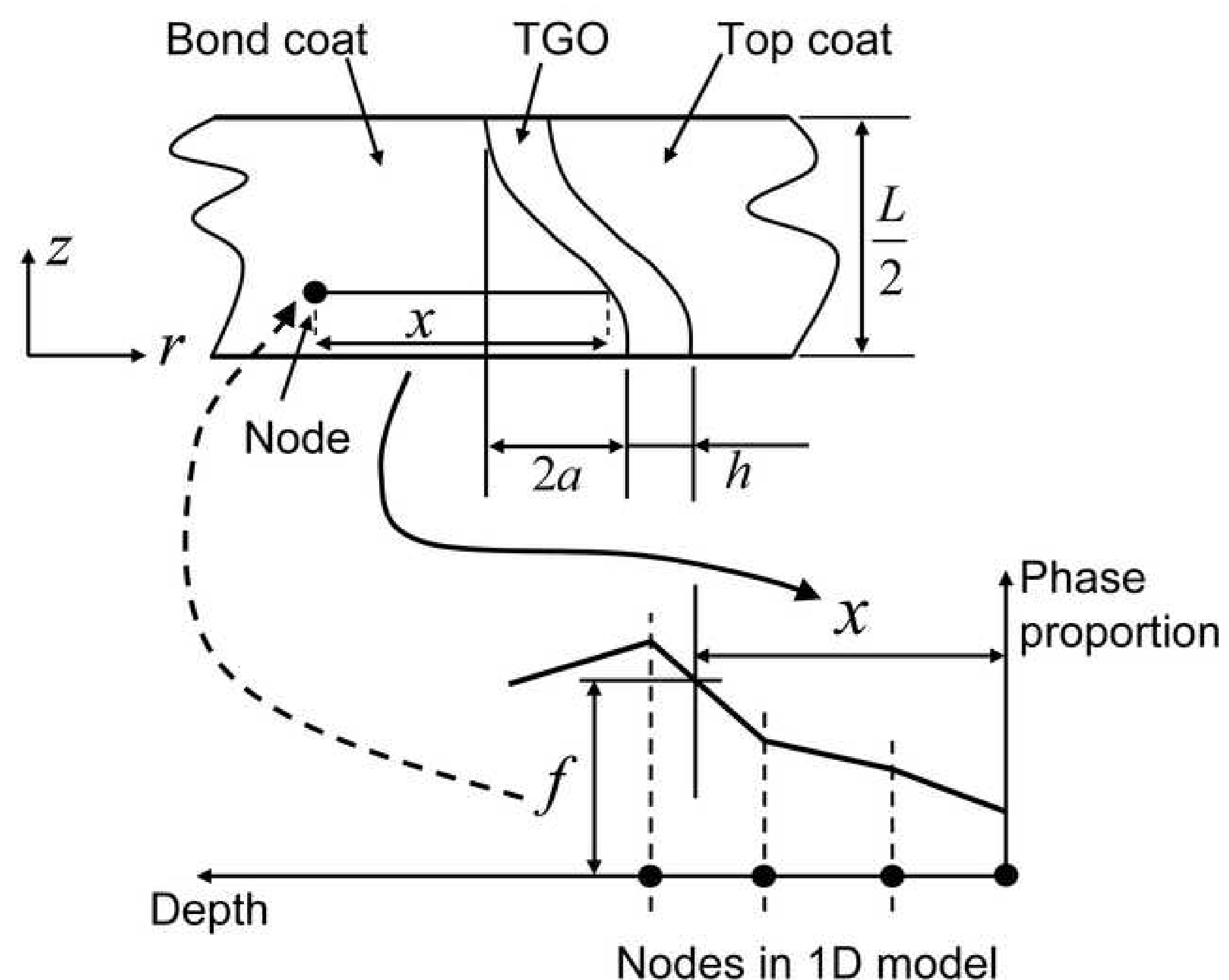

Nodes in 1D model 


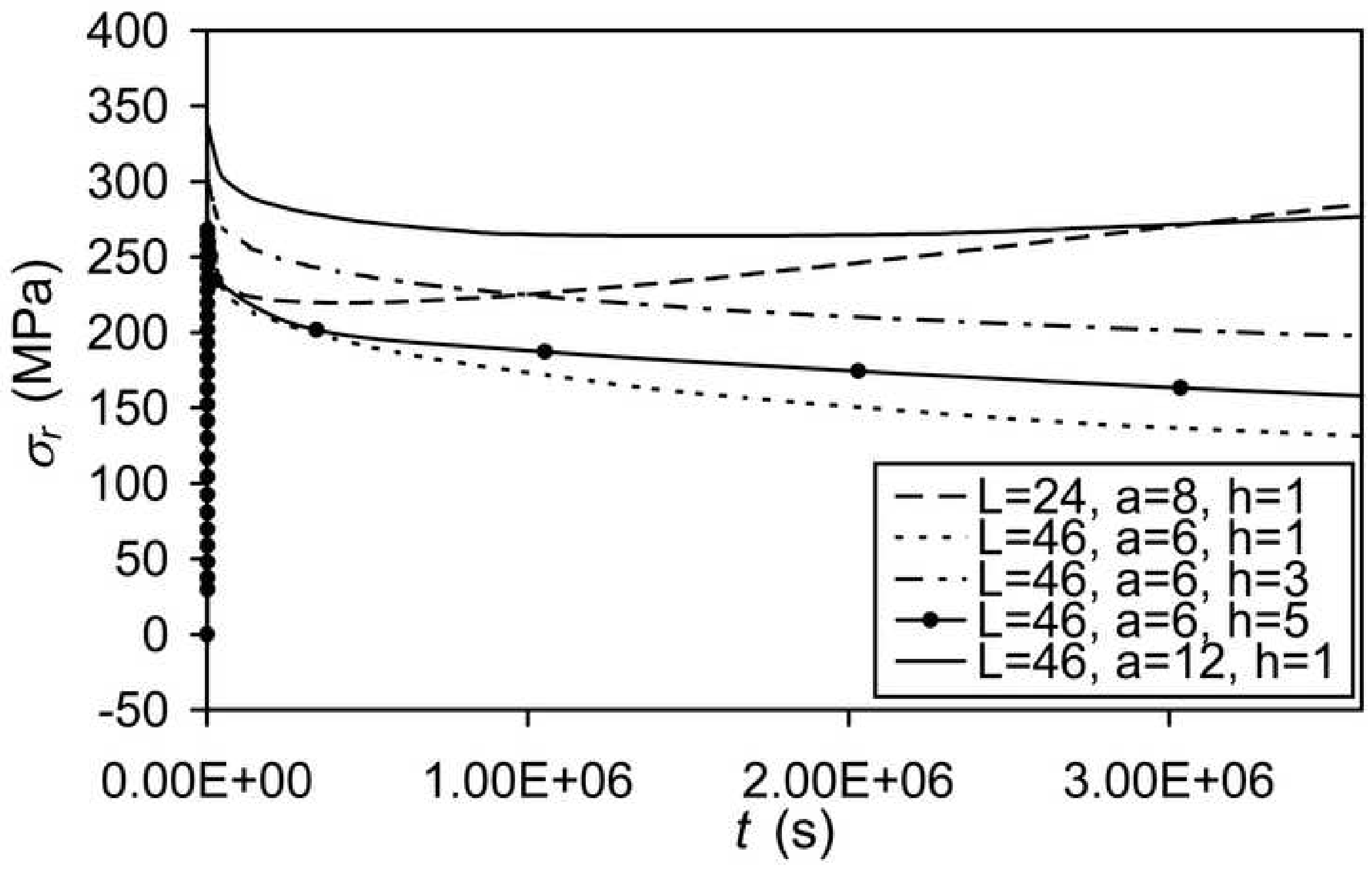


Click here to download high resolution image

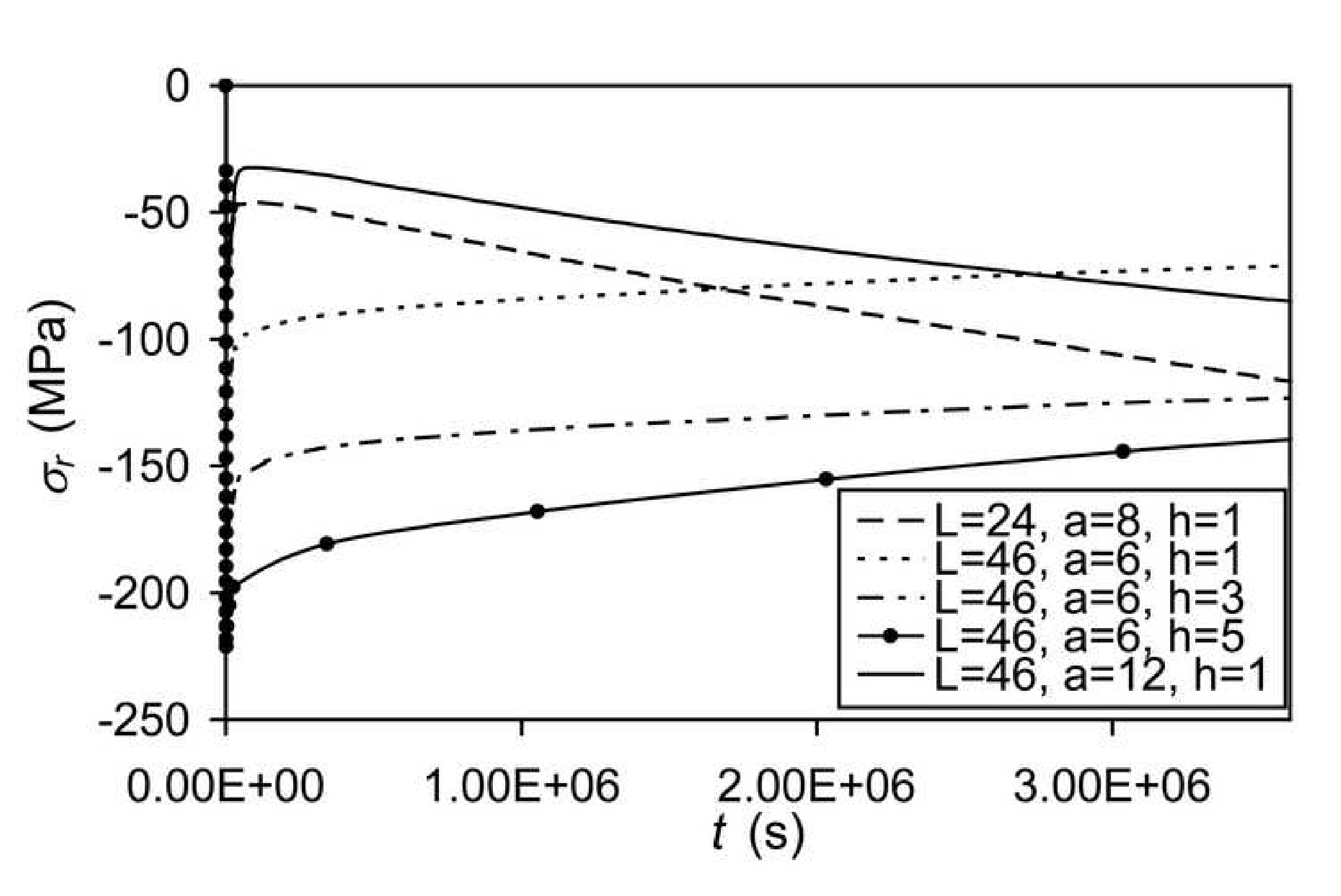

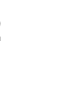

(
} 


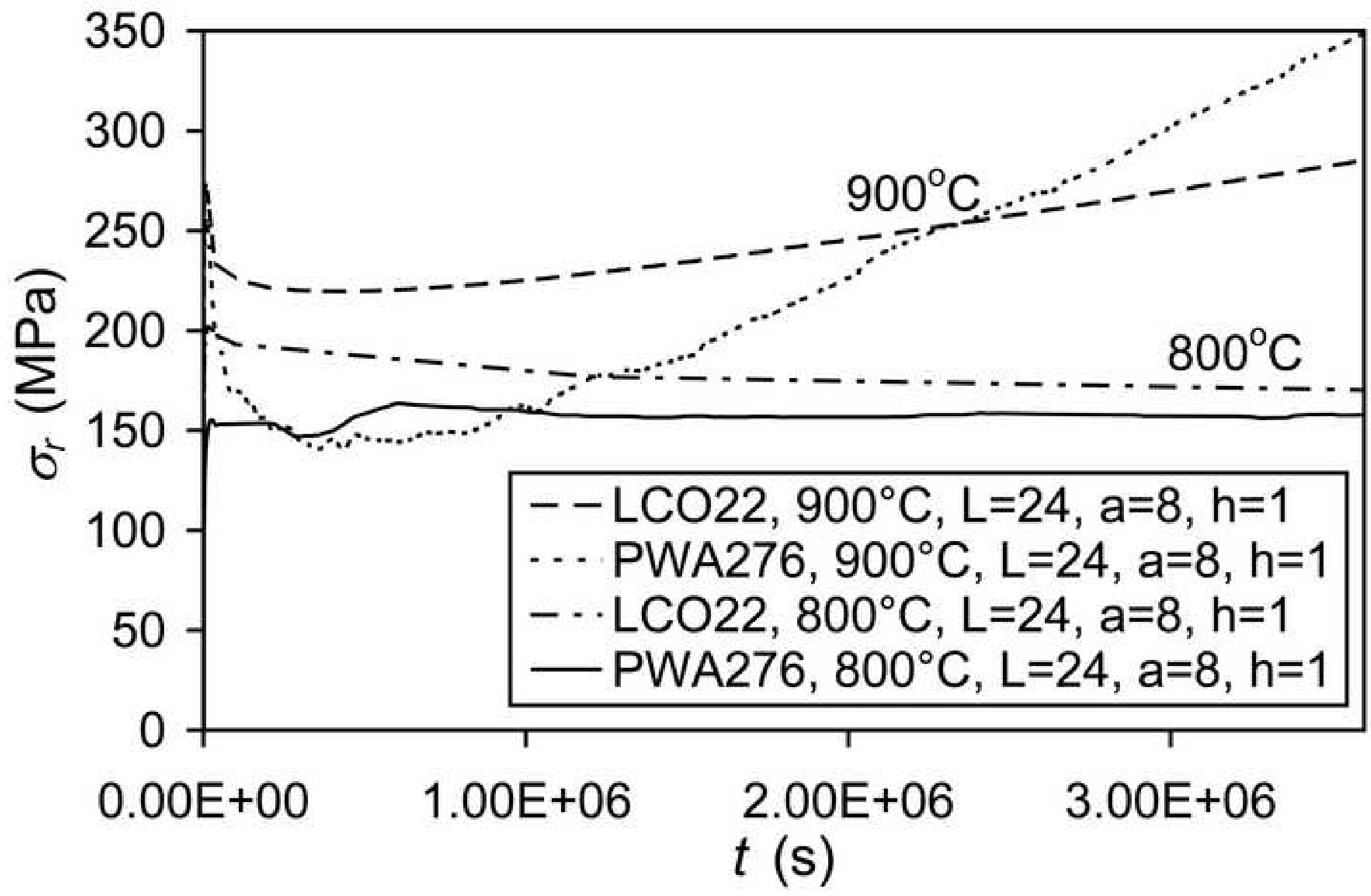




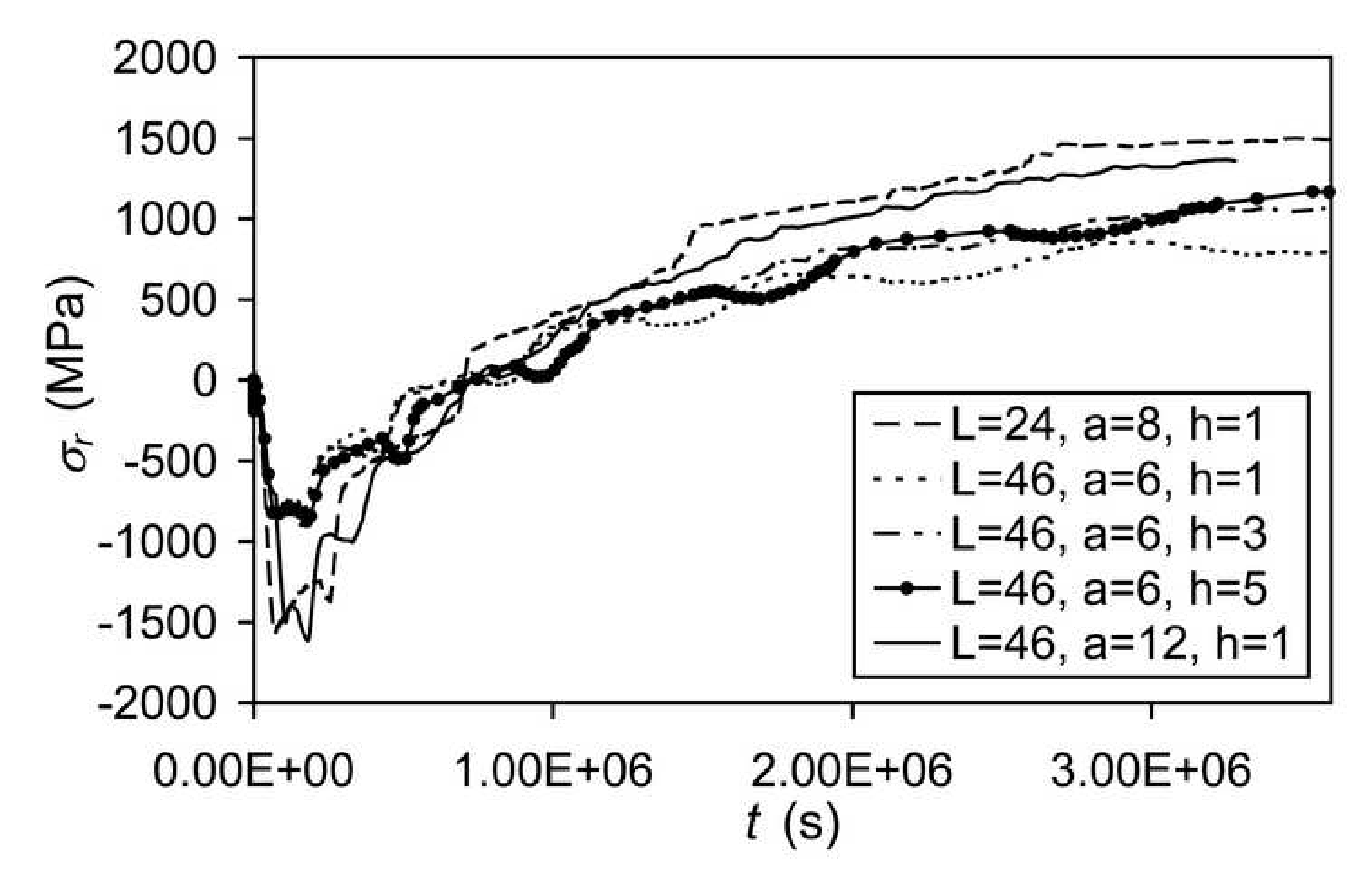




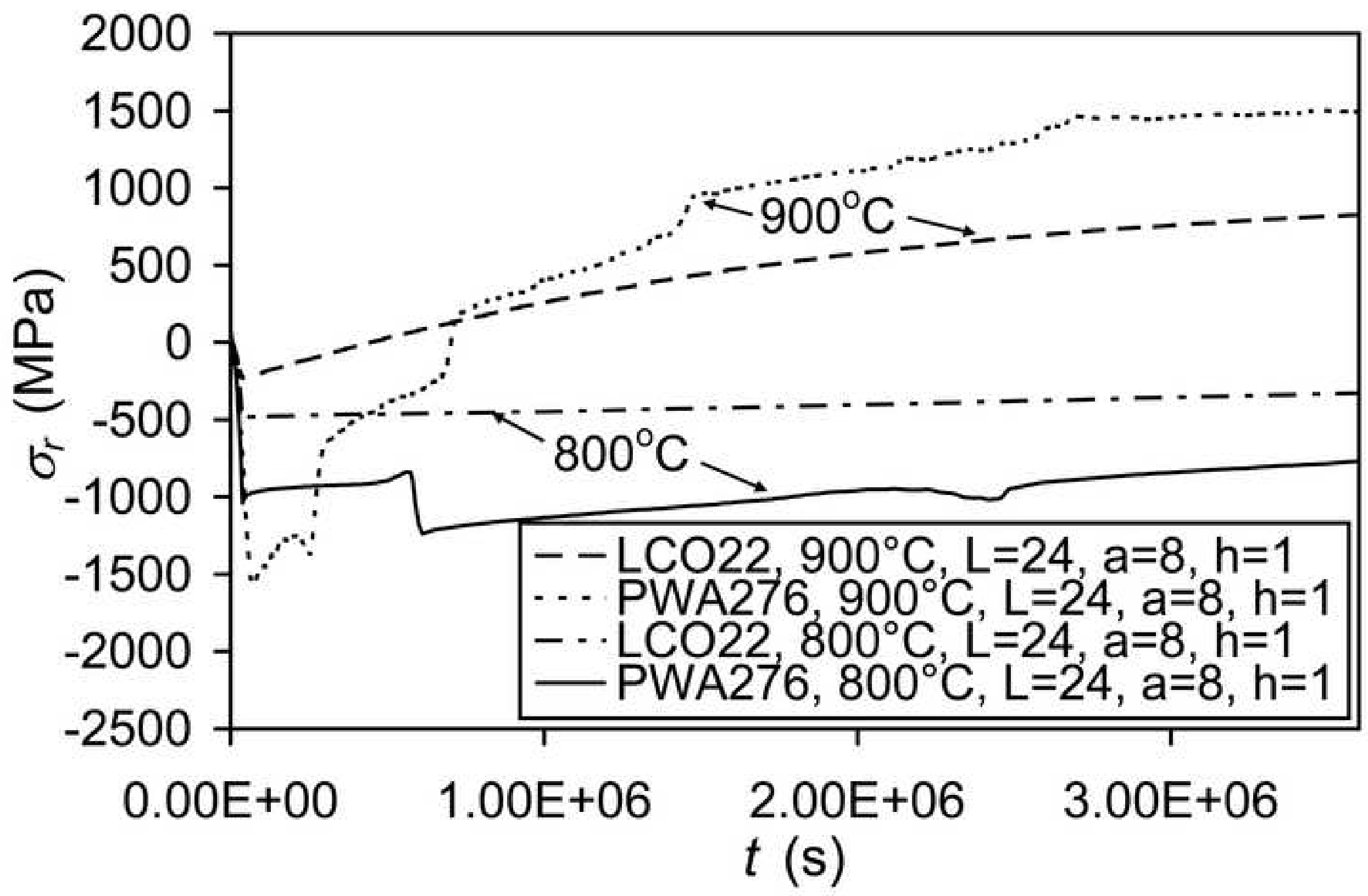

